\title{
Genotype x Environment Interaction and Its Stability Measures; Major emphasis in Arabica Coffee: A Review
}

\author{
Lemi Beksisa* \\ Ethiopian Institute of Agricultural Research, Jimma Agricultural Research Center. \\ P.O. Box, 192, Jimma, Ethiopia
}

\begin{abstract}
Understanding the implication of genotype $\mathrm{x}$ environment interaction (GEI) structure is an important consideration in plant breeding programs. The phenotype of an individual is determined by both the genotype and the environment, these two effects are not always additive which indicates that genotype $\mathrm{x}$ environment interactions (GEI) are present. The presence of genotype $\mathrm{x}$ environment interaction contributes to the unreliability 'of crop yield over a wide range of environments. The occurrence of large genotype $\mathrm{x}$ environment interaction makes the selection of superior genotypes difficult and inhibits progress from selection. It prevents the full understanding of genetic control of variability. In the absence of GEI, the superior genotype in one environment may be regarded as the superior genotype in all, whereas the presence of the GEI confirms particular genotypes being superior in particular environments. Therefore, it is important to understand the nature of genotype $\mathrm{x}$ environment interaction to make testing and selection of genotypes more efficient. A variety of statistical procedures are available to analyze the results of multi-environment trials. Additive Main Effects and Multiplicative Interaction (AMMI) model which combines the conventional analyses of variance for additive main effects with the principal components analysis (PCA) for the non-additive residuals and Genotypic Main effect plus genotype by environment interaction (GGE) biplot are two popular graphical analysis systems for multi-environment trials. Other method like the regression of genotype means on the environment means is also worthwhile.
\end{abstract}

Keywords: Additive Main Effects and Multiplicative Interaction, genotype x environment interactions, Stability DOI: $10.7176 /$ ALST/89-01

Publication date:August $31^{\text {st }} 2021$

\section{Introduction}

Coffee (Coffea arabica L.) belongs to the genus Coffea in the Rubiaceae family, and is a self-fertile allotetraploid species that is mostly grown in the tropical and subtropical regions (Berthaud \& Charrier 1988). Among more than 100 species in the genus Coffea, Coffea arabica L. (arabica coffee) which is the only tetraploid species $(2 n=4 x=44)$, and Coffea canephora $P$. (Robusta coffee) diploid $(2 n=2 x=22)$ chromosomes are the two most important commercial species (Davis et al. 2006). Coffea Arabica L. considered as a high quality coffee and contributes more than 70 percent of the world coffee production. It is the second most exported commodity after oil worldwide (Gray et al. 2013) and represents a significant source of income to several Latin American, African and Asian countries.

Ethiopia ranks first in Africa and fifth in the world after Brazil, Vietnam, Colombia and Indonesia in coffee production and is the tenth coffee exporter with less than 5 percent share of the world. During 2020 cropping season, the total area under production estimated to 540000 hectares and the production is estimated to be 450,000 metric tons (USDA, 2020). In Ethiopia, coffee grows under a wide range of environmental conditions between altitudinal ranges from 550 to $2750 \mathrm{~m}$ above sea level. Within the range of mid to high sub-humid agroecology is, however, the most important coffee producing environment in the country is between altitudinal range from 1500 to $2500 \mathrm{~m}$ above sea level with ideal minimum and maximum air temperature of 15 and $30^{\circ} \mathrm{C}$, respectively (Ayana et al. 2016).

In spite of the fact that Ethiopia is the center of origin and diversity for the Arabica coffee and the important role it plays in the national economy of the country, Ethiopian coffee industry is threatened by a number of constraints. The major factors contributing to low yield in Ethiopia include: lack of improved cultivars for each ecological zone of the country, disease mainly coffee berry disease (CBD), coffee wilt disease (CWD) and coffee leaf rust (CLR) and unimproved management practices (Eshetu 1997; Bayeta 2001).

Low yield due to adaptation problem to a range of ecological condition is another problem that challenges the Ethiopian coffee industry. The performance of a crop variety is the resultant effect of its genotype and the environment in which it is grown. The effects of genotype and environment on phenotype are not independent. The phenotypic response to change in environment is not the same for all genotypes. Very often, breeders encounter situations where the relative rankings of varieties change from location to location and/or from year to year. Inconsistency in the performance of genotypes or a change in the magnitude of the difference between genotypes under a range of environment is termed as genotype-environment (GE) interaction (Comstock and Moll 1963; Dabholkar 1999). 
Knowledge of extent and patterns of GEI effect can help to effectively design appropriate breeding strategies, optimize varietal selection vis-a-vis the target production environments, and to define suitable areas of recommendation domain where, a given cultivar can be better adapted (Yan \& Hunt 2001). In addition to this, knowledge of extent and patterns of GE interaction can help plant breeders to reduce the cost of genotypes evaluation by eliminating unnecessary spatial and temporal yield trials (Basford \& Cooper 1998). It is therefore, essential to quantify the interaction of the genotype with the environments in which they were assessed. In addition, understanding of the causes of the GEI is extremely important because it can contribute to determine the breeding objectives, identify ideal test conditions and recommend regional cultivars with better adaptation. Therefore, the objectives of this paper is;

$>$ To review the effects of genotype x environment interaction in Arabica coffee genotypes

\section{Genotype X Environment Interaction}

The increase in population and the subsequent rise in the demand for agricultural produce are expected to be greater in regions where production is already insufficient. The necessary increase in agricultural production represents a challenge to local farming systems and must come mainly from increased yield per unit area, given the limited scope for extension of cultivated land worldwide. To meet this requirement, various crop improvement programs all over the world have been initiated. As far as the success of a plant breeding program depends on its ability to provide farmers with genotypes with guaranteed superior performance (phenotype) in terms of yield and/or quality across a range of environmental conditions, it is necessary to have an understanding of the factors leading to a good phenotype.

Under any crop improvement program ,a sample of promising genotypes performance are tested each year at a number of site, representing the major growing area of the crop with a view to identify genotypes which poses the dual qualities of high-yield sustainability to adverse changes in environmental condition. It is observed that a specified difference in environment may produce differential effect on genotype. This interplay of genetic and non-genetic effects causing differential relative performances of genotypes in different environments is called Genotype x Environment Interaction (GEI) (Parul Saini et al. 2013).

GEI can be defined in two forms as qualitative (rank changes) and quantitative (absolute differences between genotypes). GEI also defined as the differential response of crop genotypes to changing environmental conditions. When varieties are grown at several locations for testing their performance, their relative rankings usually do not remain the same. GEI makes it difficult to select the best performing and most stable genotypes and is an important consideration in plant breeding programs because it reduces the progress from selection in any one environment (Hill 1975; Yau 1995). The phenotype of an organism is determined by the combined effects of the environment and the genotype which interact with one another. Thus, the basic model that includes $\mathrm{G} \times \mathrm{E}$ interaction is $\mathrm{P}=\mathrm{G}+\mathrm{E}+\mathrm{GE}$. This model can be written from statistical stand point as $\mathrm{P}_{\mathrm{ij}}=u+\mathrm{G}_{\mathrm{i}}+\mathrm{E}_{\mathrm{j}}+(\mathrm{GE})_{\mathrm{ij}}$, where $u$ is the overall mean, $G$ is the effect of genes of the $\mathrm{i}^{\text {th }}$ genotype and $\mathrm{E}$ is the effect of environment at $\mathrm{j}^{\text {th }}$ location. If follows from the model that, for a given genotype, there can be many phenotypes depending up on the $\mathrm{E}$ and $\mathrm{G} \times \mathrm{E}$ interaction. The association between the expressions of the character in different environments is a function of the degree to which the same genes influence genetic variation in the different environments. The greater the degree of GEI results, the more dissimilar the genetic systems controlling the physiological processes conferring adaptation in the different environments.

Statistically, GEI detected as a significantly different pattern of response among the genotypes across environments, i.e. there is a significant difference in the relative performance of the genotypes when they are grown in different environments. Biologically, this will occur when the contributions (level of expression) of the genes regulating the trait differ among environments. This conditional contribution of genes to the expression of a trait is considered to be the biological basis of GEI and what we would like to detect with our statistical tests. Allard (1960) described the biological complexity underlying GE virtually all phenotypic effects are not related to the gene in any simple way. Rather they result from a chain of physicochemical reaction and interactions initiated by genes but leading through complex chains of events controlled or modified by other genes and the external environments. Allard and Bradshaw (1964) emphasized that the stability with which we are concerned does not imply general constancy of phenotype in varying environments. It implies stability in those aspects of phenotype, especially yield and quality that are economically important. Such stability may in fact depend on holding some aspects of morphology and physiology in steady state and allowing others to vary. Thus, the stable varieties will show low genotype $\mathrm{x}$ environment interaction for agriculturally important characters, particularly yield, but not necessarily for other characters.

To a geneticist, environment is the sum total of physical, chemical and biological factors that influence the development of an organism such as different soil types, soil fertility levels, moisture levels, temperatures, cultural practices, foliar and stem diseases, soil borne constraints and penology (Fehr 1991). Such interactions complicate testing and selection in breeding programs and result in reduced overall genetic gains of the desired traits (Shafi \& Price 1998). The environments are often considered to have been sampled from some target 
population of environments in a series of experiments. The process of sampling environment is generally associated with testing the genotypes at a number of sites for a number of years. Therefore, environments are commonly defined as particular site year combination (Basford \& Cooper 1998).

\subsection{Patterns of Genotype by Environment interaction}

The Genotype $\mathrm{x}$ Environment interaction term represents the differential genotype responses under different environmental conditions. In most situations, the relative performances of two genotypes change with the environment conditions, as a direct consequence of GE interaction. Therefore, one of the most important objectives of the analysis of phenotypic stability is to identify the genotypes whose phenotypic performance remains stable even when the environmental conditions change. These analyses only make sense if GE interactions are present (Hussein et al. 2000).

According to Furtado Ferreira et al. (2006) example, in Figure 1, the mean performances of two genotypes (A and B) are shown in two environments (E1 and E2) to illustrate the environmental effect, the presence and the absence of an interaction effect, and the two basic types of interaction. Figure 1 (a) and (b) show the absence of an interaction effect. In these cases the genotype lines are parallel, with genotype A showing a higher response than genotype B, and absence of environmental effect in 1(b). Figure 1 (c) and (d) show interaction effects. In 1 (c) the interaction is of a simple type, with genotype B superior for both environments E1 and E2. In 1 (d) the interaction is complex. This is the most important case for the plant breeder, because genotype A has the lowest mean in environment E1, but the highest mean in environment E2. Most real situations show a mixture of cases 1 (a) to 1 (d).
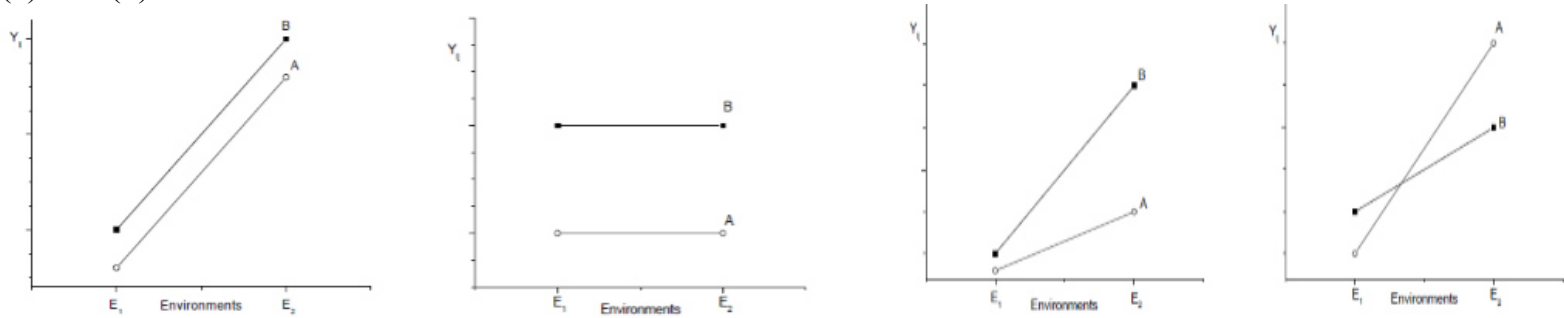

Figure: 1. Patterns of the genotype behaviors in different environments

\subsection{Cause of Genotype $x$ Environment Interaction (GEI)}

GEI is a function of the environmental variables and a function of the genotypic effects. An understanding of environmental and genotypic causes of GEI is important at all stages of plant breeding, including ideotype design, parent selection and selection based on traits (Jacson et al. 1996). When a significant GEI is present, researchers are interested to know the cause of the interaction in order to make accurate predictions of genotype performance across different environments. An understanding genotypic response to individual factors aids in interpreting and exploiting GEI. At a level other than optimal, an environmental factor represents a stress.

In general, both biotic and abiotic factors are said to be the main contributors for GEI. The adverse effects of abiotic stresses can range from simple inhibition of enzymes function to the production of random lesions in proteins and nucleic acid. Various causes have been described as causes of genotype $\mathrm{x}$ environment interaction; for instance altitude, daily temperature fluctuations, amount and distribution of rainfall and the physical and chemical properties of the soil are very important factors. Basford and Cooper (1998) reviewed a number of defined causes for GEI in wheat in Australia among which foliar and stem diseases are some factors. These environmental constraints are distinguished from the soil borne problems, because their incidence within environments is usually easier to detect by the presence of signs and/or symptoms of the disease on the above ground parts of the plant. Here it is the combination of genetic variation for resistance to a disease and variation among environments for the presence and level of infection by the pathogen that indirectly give rise to GEI for the economically important traits (yield and quality). Similarly variation in phenology with the availability of the water resources and tolerance of resistance level for drought induces strong genotype $\mathrm{x}$ environment interaction (Cooper et al. 1994).

\section{Significance of Genotype by environment interaction in plant breeding}

Crop breeders have been striving to develop genotypes with superior grain yield, quality and other desirable characteristics over a wide range of different environmental conditions. However, GEI are of major scenarios to breeders in the process of developing improved varieties. What breeders can do to overcome the problem depends upon the relative importance of variance components. Moreover, breeding program aimed to develop stable genotypes also depend upon whether a breeder is dealing with predictable or unpredictable environmental variation. Whenever dealing with predictable environmental variation, the first step that should be taken is to identify the differences. There is no difficulty when differences are recognizable, for example, differences in the 
seasons such as varieties to be developed for the rainy season or post-rainy season. Breeders can develop varieties suitable for both seasons because environmental variation is defined.

For variety trials, which are tested in the same locations (L) and genotypes (G) and over years (Y), GE analysis of variance may be partitioned into components due to G x L, G x Y and G x L x Y. Significance of mean square for G x L generally suggests that the region for which genotypes are being produced comprises of a number of special environments. In such circumstances the geographic region could be subdivided into sub regions which are relatively homogeneous. Varieties should be bred which are specifically adapted to these ecotypes. Implication of G x Y interaction is very different from G x L interaction. This is so because year-to year fluctuations cannot be predicted in advance and breeders can hardly aim their program to develop varieties suited to particular years (Dabholkar 1999).

It is relatively easier to develop varieties specifically adapted to predictable environmental situations than to breed for unpredictable environmental variations. For example, saline soils can be corrected by certain agronomic practices or by addition of some amendments. According to Allard and Bradshaw (1964) "a variety which can adjust its genotypic or phenotypic state in response to transient fluctuations in environment in such a way that it gives high and stable economic returns for place and year, is termed as well buffered". Plant breeders generally agree that the new variety must show a high degree of stability in performance. According to DeLacy et al. (1996), phenotypic performance of genotypes in combination with different environments can be analyzed to qualify the amount of variation attributable to the effects of the environment, genotype, and GEI.

The existence of GEI complicates the identification of superior genotypes for a range of environments. GEI can be an outcome of genotype rank changes from one environment to another, a difference in scale among environments, or a combination of these phenomena. According to Becker \& Léon (1998), cultivar rank changes are of greater importance than scale change interactions in cultivar trials conducted over a series of environments. Hence, GEI is critical only if it involves significant crossover interactions (significant reversal in genotypic rank across environments) (Becker \& Léon 1988).

\section{Genotype x Environment Interaction in Arabica Coffee (Coffea arabica L.)}

The inferences of various investigations are not consistent and differ greatly according to the material used and place of experimentation. The variation in genotypic response from one environment to another is an intrinsic part of a genotypic behavior and without its estimation, assessment of a genotype remains incomplete (Westcott 1987). Few researchers in Ethiopia have studied this phenomenon and tried to specify and estimate the stability and adaptability of many coffee characters and their response to changing environments (Yonas \& Bayetta, 2008; Lemi et.al. 2016).

The study of bean yield stability of coffee cultivars tested at multi locations in Ethiopia within the domain of the main coffee growing ecologies of the country, showed a significant effect of location $\mathrm{x}$ genotype interaction indicating differential response of genotypes across the locations (Mesfin \& Bayetta 1987). They stated that, none of the cultivars tested across the different locations showed linear response with changes in environmental conditions for yield and most of yield related traits showing their specificity only for defined ecological zones. On the basis of their study, they stressed on the need for testing coffee cultivars over a wide range of ecological conditions before making decision either for specific or extensive use of cultivars. Yonas and Bayetta (2008); Meaza et al. (2011), Lemi et al.(2018) \& Yonas et al. (2014) also reported significant effect of GEI in yield of coffee Arabica. Similar studies in other countries by different workers have also indicated the presence of strong significant GEI (Agwanda \& Owuor 1989; Agwanda et al. 1997) in Coffea arabica L. However, these authors at the same time indicated the presence of stable cultivars in the population of their Coffea arabica materials. They concluded that selecting high yielding genotypes with a linear response to changes in environment is also possible. Similarly, Marie et al. (2020) also reported the presence of GEI in Coffea arabica L. but with some stable cultivars that stabilize coffee bean yield in Coffea canephora materials. The quality of coffee is also strongly influenced by environmental factor (Decasy et al. 2003; Agwanda et al. 2003; Marie et al. 2020) clearly showed that climate is one of the important factor in determining quality of coffee beverage (Silva et al. 2005). It is also depends up on the genetic make-up of the variety and the environmental conditions in which it is grown.

Review of previous research results indicated inconsistent effects of GEI on cup quality. Walyaro (1983) reported relatively lower GEI effects on quality characters. Van der Vossen (1985) reported non-significant GEI effects on quality characters, such as bean size and cup quality. Roche (1995) evaluated the cup quality of 15 Arabica coffee cultivars by coffee tasters throughout United States of America and reported general consistency in the overall ranking of cultivars between two seasons. Therefore, quality evaluations based on multi-site trials could also be used to identify environments that best reveal differences in genetic potentials amongst varieties and hence useful as selection or test sites (Agwanda et al. 2003). This could improve the efficiency with which selection for superior quality could be attained. 


\section{Concept of Stability}

The goal of any plant breeding is to produce genotypes that are optimum for the condition under which they will grow. One approach is to develop genotypes that are widely adapted over wide range of environmental conditions. These stable genotypes provide a stock from which superior genotypes may be selected (Allard \& Bradshaw 1964). Although it is important to detect genotypes $\mathrm{x}$ environment interaction by conducting yield trials over a series of environments, this alone gives no measure of the stability of individual genotypes. Hence stability measurements are important since they give an indication of the adaptability of genotypes to general or specific condition (Getinet 1988).

Stability of a genotype yield is the ability of a genotype to produce or perform under stressful conditions and yet be able to respond (Lin et al. 1986). Tollenaar \& Lee (2002) defined stability as a measure of the ability of a genotype to maintain its relative performance across wide environments. The stability with which a plant breeder is concerned implies stability in those aspects of phenotype which are important economically, such as grain yield and quality (Zelalem 2011). Such stability may depend upon holding some aspects of morphology and physiology in a steady state but allowing others to vary. In this way, the desirable varieties will show low GEI for agriculturally important characters, especially yield, but not necessarily for all characteristics.

Stability has been described in many different ways over the years and there have also been different concepts of stability (Lin et al., 1986). Researchers use the terms adaptation, phenotypic stability and yield stability in different ways (Becker and Léon, 1988). Stability in common usage implies consistency in performance that would mean minimum variation among environments for a particular genotype (Chahal \& Gosal 2002).

Stability is either static or dynamic. In static stability, performances of the genotype remains unchanged regardless of the environmental conditions and in dynamic conditions, performance of a genotype changes in a predictable manner across a wide range of environmental conditions (Tollenaar \& Lee 2002). In addition, static stability is an absolute measure, while dynamic stability is a relative measure. On the other hand dynamic stability, also termed as agronomical concept of stability, implies that a stable genotype should always give high yield expected at the level of productivity of the respective environments, i.e., a variety with GE interaction as small as possible (Becker 1981; Dabholkar 1999).

\section{Statistical Methods used for GEI and Stability Analysis}

If the GEI variance is found to be significant, one or more of the various methods for measuring the stability of genotypes can be used to identify the stable genotypes and also best varieties for limited environments (Whichwon-where view). Among the several stability parameters developed by different investigators, the most commonly used statistical tools to determine the pattern of genotypic responses across environments were discussed below.

\subsection{Additive main effects and multiplicative interaction (AMMI) model}

Additive main effects and multiplicative interaction (AMMI) is a model which incorporates the additive and multiplicative components into an integrated and powerful analysis to give plant breeders and other plant scientists a powerful statistical tool for the analysis of multi-location trials (Zobel et al. 1988; Gauch \& Zobel 1989). The development of high yielding cultivars with wide adaptability is the ultimate aim of plant breeders. However, attaining this goal is made more complicated by GEI (Gauch \& Zobel 1996). According to Zobel et al. (1988), considering the three traditional models, analysis of variance (ANOVA) fails to detect a significant interaction component, principal component analysis (PCA) fails to identify and separate the significant genotype and environment main effects and linear regression models accounts for only a small portion of the interaction sum of squares. But AMMI analysis reveals a highly significant interaction component that has a clear agronomic meaning and it has no specific design requirements, except for a two-way data structure.

The AMMI method is used for three main purposes. The first is model diagnoses, AMMI is more appropriate in the initial statistical analysis of yield trials, because it provides an analytical tool of diagnosing other models as sub cases when these are better for particular data sets (Gauch 1988). Secondly, AMMI clarifies the GEI, summarizes patterns and relationships of genotypes and environments (Zobel et al. 1988; Crossa et al. 1990). The third use is to improve the accuracy of yield estimates. Gains have been obtained in the accuracy of yield estimates that are equivalent to increasing the number of replicates by a factor of two to five (Zobel et al. 1988; Crossa 1990). Such gains may be used to reduce testing cost by reducing the number of replications, to include more treatments in the experiments or to improve efficiency in selecting the best genotypes.

The AMMI model combines the analysis of variance for the genotype and environment main effects with principal components analysis of the GEI. It has proven useful for understanding complex GE interactions. It also combines analysis of variance (ANOVA) into a single model with additive and multiplicative parameters. The principal components analysis of AMMI partitions GEI into several orthogonal axes, the interaction principal component analyses (IPCA). 
Since AMMI has the biplot feature, genotypes and environments are plotted on the same diagram, facilitating inference about specific interactions of individual genotypes and environments by using the sign and magnitude of IPCA 1 values. Any genotype with a IPCA 1 value close to zero shows general adaptation to the tested environments. A large genotypic PCA1 scores reflects more specific adaptation to environments with IPCA 1 scores of the same sign. Integrating biplot display and genotypic stability statistics enable genotypes to be grouped based on similarity of performance across diverse environments. Plant breeders can easily select from a bi-plot those genotypes that are high yielding and stable (little interaction with sites), and also those entries that yield well at specific sites (Yau 1995).

From earlier yield trial of GEI in coffee Arabica, Yonas et al. (2014), Meaza et al. (2011) Lemi et al. (2016) in Ethiopia and Wamatu et al. (2003) in Kenya demonstrated the application of AMMI in the analysis of genotype $\mathrm{x}$ environment interaction in Arabica coffee. Many other workers including Zobel et al. (1988); Crossa et al. (1990) using multiplication yield data, demonstrated the application of AMMI in the analysis of genotype $\mathrm{x}$ environment interaction.

\subsection{Genotype main effect and genotype x environment interaction $(G G E)$ biplot analysis}

Genotype main effect and GEI biplot analysis is another important model for the evaluation of the genotype performance across testing environments and it enables visual evaluation of genotype, environment and GEI in multi environment trial. The GGE biplot is constructed by plotting the first principal component scores of the genotypes and the environments against their respective scores for the second principal components that result from SVD (singular value decomposition) of environments centered or environment standardized. GGE biplot also effective tool for genotype evaluation, determining the mean performance and stability and environmental evaluation (the power for discriminate among genotypes in target environment (Yan and Kang, 2003). Moreover, even if the AMMI1 biplot (Zobel et al., 1988) is the most well-known, the polygon view of a biplot is the best way to visualize the interaction patterns between genotypes and environments and to effectively interpret a biplot (Farshadfar et al. 2013). Therefore, visualization of the "which-won-where" pattern of MET data is particularly very important for studying the possible existence of different mega-environments in a region (Yan et al. 2000; Yan et al. 2001).

\subsection{Superiority index (Pi)}

Lin and Binns (1988) proposed a superiority measure (Pi), which is defined as the distance mean square between the genotype response and the maximum response. They described that cultivar superiority measure involves calculations (across environments) of the mean square difference between the performance of a genotype and the best genotype within a given environment. It measures mean performance and stability simultaneously. The smaller the value of $\mathrm{Pi}$, the lesser its distance to the genotype with maximum yield and the better the genotype is (Crossa 1990). Different researchers, Fantaye (2011) in durum wheat and Naser et al. (2012) in lentil genotypes used this stability parameter to identify high yielding and stable genotypes across different environments.

\subsection{Static stability coefficient (SSC)}

The Static Stability Coefficient is defined as the variance around the genotype's phenotypic mean across all environments. This provides a measure of the consistency of the genotype, without accounting for performance. It is based on environmental variances i.e. the variance of yields of each genotype over test environments (Lin et al. 1986; Becker \& Leon 1988). A low value (closer to zero) of this coefficient indicates a better fit of a genotype to the static stability concept.

\subsection{Wricke's ecovalence $\left(W^{2} i\right)$}

Wricke (1962) defined the concept of ecovalence, to describe the stability of a genotype, as the contribution of each genotype to the GEI sum of squares. The ecovalence $\left(\mathrm{W}^{2} \mathrm{i}\right)$ or the stability of the $\mathrm{i}^{\text {th }}$ genotype is its interaction with environments, squared and summed across environments. The genotypes with lower amount of $\mathrm{W}^{2} \mathrm{i}$ could be considered as stable, while the genotype with higher value of $\mathrm{W}^{2} \mathrm{i}$ considered as unstable. Like static stability, the Wricke's Ecovalence does not account for genotype performance.

\subsection{AMMI stability value (ASV)}

AMMI Stability Value (ASV) is the distance from the coordinate point to the origin in a two-dimensional plot of IPCA1 scores against IPCA2 scores in the AMMI model (Purchase, 1997). Because the IPCA1 score contributes more to the GEI sum of squares, a weighted value is needed. This weighted value was calculated for each genotype and each environment according to the relative contribution of IPCA1 to IPCA2 to the interaction sum of squares. Genotypes with lower ASV values are considered more stable than genotypes with higher ASV. The ASV, which uses two IPCA scores to produce a balanced measurement between them, can be useful in situations where the two first IPCAs accounted for considerable amount of genotype $\mathrm{x}$ environment interactions (Anley et 
al. 2013).

\subsection{Yield stability index (YSI)}

This parameter was developed by (Farshadfar et al. 2011). Stability per se should however not be the only parameter for selection, because the most stable genotypes would not necessarily give the best yield performance (Mohammad et al., 2007). Hence, there is a need for approaches that incorporate both mean yield and stability in a single index, that is why various authors introduced different selection criteria for simultaneous selection for yield and stability. In this regard, as ASV takes into account both IPCA1 and IPCA2 that justify most of the variation in the GE interaction. The rank of ASV and yield mean in such a way that the lowest ASV takes the rank one, while the highest yield mean takes the rank one and then the ranks are summed in a single simultaneous selection index of yield and yield stability named as: yield stability index (YSI). The least YSI is considered as the most stable with high bean yield and the reverse is true.

\section{Summary and Conclusion}

The occurrence of the genotype $(\mathrm{G}) \mathrm{X}$ environment (E) interaction effect further complicates the selection of superior genotypes for a target population of environments. It is therefore, before deciding any variety to use under wider agro ecology, it is must to test in multi environments to identify stable genotype and environment and ideal genotype and environment by using the most efficient stability estimating models. Such information is important, because genotype-environment interactions can have major implications on the potential for evolutionary responses to selection. One of the most common methods in a G X E interaction study is to compute the simple averages across replications for a genotype in an environment and then analyzing the means. An alternative method of analyzing the data in a two-way table of means is the Additive Main Effects and Multiplicative Interaction (AMMI) model which combines the conventional analyses of variance for additive main effects with the principal components analysis (PCA) for the non-additive residuals. Whereas, the recently popularized stability analysis so called Genotype and Genotype Environment interaction (GGE) biplot is also to be used since it has many important property of a true biplot, specifically to know which-won-where pattern clearly

\section{References}

Agwanda, C.O., P. Baradat, A. Eskes, C. Cilas \& Charrier, A. (2003), "Selection for bean and liquor qualities within related hybrids of Arabica coffee in multi local field trials", Euphytica, 131(1), pp.1-14.

Agwanda, C.D., P.C. Baradat \& Charrier, A. (1997), "Genotype x environment interaction and its implications on selection for improved quality in Arabica coffee (Coffea arabica L.)" In COLLOQUE Scientifique International sur le Café, 17, Nairobi (Kenya), Juillet, pp. 20-25.

Allard, R.W. \& Bradshaw, A. D. (1964), "Implications of genotype-environmental interactions in applied plant breeding", Crop science, 4(5), pp.503-508.

Anley, W., Zeleke, H. \& Dessalegn, Y. (2013), "Genotype X environment interaction of maize (Zea mays L.) across North Western Ethiopia”, Journal of Plant Breeding and Crop Science, 5(9), pp.171-181.

Ariyo, O.J. (1995), "Correlations and path-coefficient analysis of components of seed yield in soya beans", African Crop Science Journal, 3(1), pp.29-33.

Basford, K.E. \& Cooper, M. (1998), "Genotype x environment interactions for wheat breeding in Australia", Australian Journal of Agricultural Research, Vol.49: pp.153-174.

Bayetta, B. (1986), "Exploration and collection of coffee germplasm in the Gambella Plai", IAR. Newsletter. 1(2): $3-5$.

Bayetta, B. (2001), "Arabica coffee breeding for yield and resistance to coffee berry disease (Colletotrichum kahawe) sp.nov," Doctoral thesis submitted to the Imperial College at Wye university of London.

Becker, H.C. (1981), "Correlations among some statistical measures of phenotypic stability", Euphytica, 30(3), pp.835-840

Becker, H.C. \& Léon, J. (1988), “Stability analysis in plant breeding” Plant Breeding 101: 1-23.

Comstock, R.E. \& Moll, R.H. (1963), "Genotype-environment interactions", Statistical genetics and plant breeding, pp.164-196

Crossa, J. (1990)," Statistical analyses of multi-location trials", Advances in Agronomy, 44,55-85.

Crossa J. H.G. Gauch \& Zobel, R.W. (1990), “Additive main effects and multiplicative interaction analysis of two international maize cultivar trials", Crop Science, 30(3), pp.493-500.

Dabholkar, A.R. (1999), "Elements of biometrical genetics", Concept Publishing Company, New Delhi, India.

Davis, A.P., Govaerts, R., Bridson, D.M. \& Stoffelen, P. (2006), "An annotated taxonomic conspectus of the genus Coffea (Rubiaceae)" Botanical Journal of the Linnean Society, 152(4), pp.465-512.

Davis AP, Gole TW, Baena S, \& Moat, J. (2012), “The Impact of Climate Change on Indigenous Arabica Coffee (Coffea arabica)" Predicting Future Trends and Identifying Priorities. PLoS ONE 7(11): e47981. 
doi:10.1371/journal.

DeLacy, I.H., Basford, K.E., Cooper, M., Bull, J.K. \& McLaren, C.G. (1996), “Analysis of multi-environment trials-an historical perspective", Plant adaptation and crop improvement, 39124.

Eshetu, D. (1997), "Coffee disease and their significance in Ethiopia", In: Asic 1 $7^{\text {th }}$ Kenya, Nairobi. VI, Pp72326.

Fantaye, A. (2011), "Genotype x environment interaction and stability analysis for yield of durum wheat (Triticum turgidum desf.) varieties in north western Ethiopia" An MSc Thesis Presented to the School of Graduate Studies of Haramaya University. p.79.

Farshadfar, E., M. Rashidi, M.M. Jowkar, \& Zali, H. (2013), "GGE Biplot analysis of genotypex environment interaction in chickpea genotypes", Europian Journal of Expermental Biology, 3, pp.417-423

Farshadfar E, Mahmodi N \& Yaghotipoor, A. (2011), "AMMI stability value and simultaneous estimation of yield and yield stability in bread wheat (Triticum aestivum L.)", Austiralian Journal of Crop Science, 5, pp. $1837-1844$

Fehr, W. R. (1991), "Principles of cultivar development", Theory and techniques, Lowa state university, USA. pp247-260.

Freeman, G.H. (1973),"Statistical method for the analysis of genotype x environment interactions", Heredity, 31:339-354

Furtado Ferreira, Daniel; Garcia Borges Demétrio, Clarice; John Manly, Bryan Frederick; de Almeida ,Machado, Amauri; Vencovsky \& Roland (2006), "Statistical models in agriculture: biometrical methods for evaluating phenotypic stability in plant Breeding" CERNE, vol. 12 (4): pp73-388.

Getinet, G. (1988), "Bread wheat improvement: Recommendations and strategies. Proceedings of the 19h National Crop Improvement Conference. EIAR, Addis Ababa. pp. 152-163.

Gauch, H.G. \& Zobel, R.W. (1996), "AMMI analysis of yield trials" pp. 85-122. In: M.S. Kang and H.G. Gauch(eds). Genotype by environment interaction. CRC Press, Boca Raton, FL.

Gray, Q., Tefera, A. \& Tefera, T. (2013), Ethiopia: "Coffee Annual Report”, GAIN Report ET-1302, USDA

Hill, J. (1975), "Genotype-environment - a challenge for plant breeding", J. Agric. Sci. vol. 85: pp477-493.

Hussein, M. A.; Bjornstad, A.; Aastveit, A. H. Sasg \& Estab, R.W. (2000), "A SAS program for computing genotype x environment stability statistics", Agronomy Journal. Vol. 92(3) pp. 454459.

Jeromela, A.M., N. Nagl, J.G. Varga, N. Hristov, A.N. Spika, M.M. Vasicand \& Marinkovic R. (2011), "Genotype x environment interaction for seed yield per plant in rapeseed using AMMI model", Pesquisa Agropecuária Brasileira, 46(2), pp.174-181.

Jackson, P., M. Robertson, M. Cooper \& Hammer, G. (1996), "The role of physiological understanding in plant breeding; from a breeding perspective", Field Crops Research, 49(1), pp.11-37.

Kang, M.S. (1993), "Simultaneous selection for yield and stability in crop performance trials", Consequences for growers. Agronomy Journal, 85(3), pp.754-757.

Krug C.A \& Carvalho, A. (1981), "The Genetics of coffee", Adv. Genet. 4:127-158.

Lemi B, Sentayew, A. Ashenafi A. \& Gerba, D. 2018, "Genotype $\times$ environment interaction and yield stability of Arabica coffee (Coffea arabica L.) genotypes", African Journal of Agricultural Research. Vol. 13(4), pp. $210-219$

Lin, C. S., M. R. Binns \& Lefkovitch, L. P. (1986), “Stability analysis: where do we stand?”, Crop science, 26(5), pp.894-900

Marie, L., Abdallah, C., Campa, C., Courtel, P., Bordeaux, M., Navarini, L., Lonzarich, V., Bosselmann, A.S., Turreira-García, N., Alpizar, E. \& Georget, F. (2020), "G× E interactions on yield and quality in Coffea arabica: new F1 hybrids outperform American cultivars", Euphytica, 216(5), pp.1-17.

Meaza Demissie; Mesfin Kebede \& Girma, T. (2011), "Additive Main Effects and Multiplicative Interaction Analysis Of Germplasms from Southern Ethiopia", Ethiop. J. Sci., 34(1):63-70.

Mesfin Ameha \& Bayetta, B. (1997), "Genotype-environment interaction and its implication on selection for improved quality in arabica coffee (Coffea arabica L.)", ASIC, 17e Colloque, Nairobi, Kenya.

Mohammadi, R., A. Abdulahi, R. Haghparast \& Armion, M. (2007), "Interpreting genotype-environment interactions for durum wheat grain yields using non-parametric methods", Euphytica, 157, pp.239-251.

Naser,S., R. Karimizadeh \& Mohammadi, M. (2012), "Genotype by environment interaction and stability analysis for grain yield of lentil genotypes" Žemdirbyst, 99, pp.305-312.

Parul, S. \& Chetan, S. (2013), "A Review on Genotype Environment Interaction and its Stability Measures", International Journal of Science and Research (IJSR), pp. 2319-7064.

Roche D. (1995), "Coffee genetics and quality" Proceedings of the $16^{\text {th }}$ International Scientific Colloquium on Coffee. Kyoto, Japan. pp. 584-588

Shafi, B. \& Price, W.J. (1998), "Analysis of genotype x environment interaction using the additive main effects and multiplicative interaction model and stability estimates", Journal of Agricultural, Biological, and Environmental Statistics, pp.335-345. 
Sivetz, M. \& Foote, H.E. (1963), "Coffee processing technology” AVI Publishing Company.

Tollenaar, M. \& Lee, E.A. (2002), "Yield potential, yield stability and stress tolerance in maize", Field Crops Research, 75(2), pp.161-169

United States Department of Agriculture,(2020), "Coffee Annual Report"

Van der Vossen, H.A. (1985)," Coffee selection and breeding”, pp.48-96. In Coffee. Springer US.

Wamatu, J.N., E. Thomas \& H.P. Piepho, (2003), "Responses of different Arabica coffee (Coffea arabica L.) clones to varied environmental conditions", Euphytica, 129(2), pp.175-182.

Walyaro, D.J. (1983), "Considerations in breeding for improved yield and quality in Arabica coffee (Coffea arabica L.)" A PhD thesis, Wageningen Agricultural University.

Wellman, F.L. (1961), "Coffee: botany, cultivation, and utilization".

Westcott, B. (1987), "A method of assessing the yield stability of crop genotypes”, J. agric. Sci.vol. 108: 267274.

Yan, W. \& Kang, M.S. (2003), "GGE Biplot analysis: a graphical tool for breeders, geneticists, and agronomists". CRC Press, Boca Raton, Florida.

Yau, S.K. (1995), "Regression and AMMI analyses of genotype x environment interactions: An empirical comparison", Agron. J. vol.87: pp121-126.

Yigzaw D. (2005), "Assessment of cup quality, morphological, biochemical and molecular diversity of C. arabica L. genotypes of Ethiopia". PhD thesis, University Free State. p. 97

Yonas, B. \& Bayetta, B. (2008), "Genotype by environment interaction and stability analysis of Arabica genotypes", Proceedings of Coffee Diversity and Knowledge Workshop EIAR, Addis Abeba, P. 58-63.

Yonas B.,Bayetta, B.\& Chemeda, F.(2014), "Stability analysis of bean yields of Arabica coffee genotypes across different environments" Greener Journal of Plant Breeding and Crop Science, pp. 018-026.

Zelalem, T. (2011), "Statistical Analysis of Genotype x Environment Interactions and Grain Yield Stability in Bread Wheat Using ANOVA and AMMI Models", An MSc Thesis presented to the School of Graduate Studies of Addis Ababa University.p.95.

Zobel, B. \& Talbert, J. (1984), “Applied forest tree improvement”, John Wiley \& Sons. pp.550.

Zobel, R.W., M.J. Wright \& Gauch, H.G. (1988), "Statistical analysis of a yield trial", Agronomy Journal, 80(3), pp.388-393. 